\title{
War against Coronavirus (COVID - 19) in Tanzania: Designing a Low Cost Automatic Water Tap
}

\author{
Herbert Wanga \\ Department of Information \\ Technology \\ University of Iringa (UoI) \\ Iringa, Tanzania
}

\author{
Thobius Joseph \\ Department of Information \\ Technology \\ University of Iringa (UoI) \\ Iringa, Tanzania
}

\author{
Mauna Belius Chuma \\ Department of Information \\ Technology \\ University of Iringa (UoI) \\ Iringa, Tanzania
}

\begin{abstract}
In December 2019, an outbreak of severe acute respiratory syndrome coronavirus 2 (SARSCoV-2) infection occurred in Wuhan, Hubei Province, China and spread across China and beyond. On February 12, 2020, WHO officially named the disease caused by the novel coronavirus as Coronavirus Disease 2019 (COVID-19). On January 30, 2020, WHO declared COVID-19 as the sixth public health emergency of international concern. One of the major preventions is frequent hand washing. An attempt has been made to design a low-cost automatic water tap as a measure to fight the spread of Coronavirus (Covid-19). The designed system uses simple, easy to get and low cost instruments. The system does not require a user to touch the water tap. It uses microcontroller to implement intelligence. The solar panel is used as a source of power. The system design uses green solution based automatic water tap. The system will be used in gatherings to avoid Coronavirus spreading. Such gathering places include hospitals, markets, bus stops, public transports, churches, mosques, and restaurants.
\end{abstract}

Keywords: coronavirus; covid-19; automatic water tap; Wuhan pneumonia; Arduino

\section{INTRODUCTION}

\subsection{Background}

Coronavirus disease (COVID-19) is caused by SARS-COV2 and represents the causative agent of a potentially fatal disease that is of great global public health concern [1].

Since December 2019, an outbreak of corona virus disease 2019 (COVID-19) occurred in Wuhan, and rapidly spread to almost all parts of China [2]. An outbreak of a novel coronavirus (COVID-19 or 2019-CoV) infection has posed significant threats to international health and the economy [3]. The outbreak of COVID-19 raised intense attention not only within China but internationally [2].

On January 30, 2020, WHO has declared COVID-19 as the sixth public health emergency of international concern [4]. As of February 9, 2020, data from the World Health Organization (WHO) has shown that more than 37,000 confirmed cases have been identified in 28 countries, with more than $99 \%$ of the cases being detected in China [4]. As of 3 March 2020, a total of 80,151 cases have been detected and confirmed in Mainland China. Internationally, there are more than 10,566 additional cases detected and confirmed in 72 countries [5]. On 23rd March 2010, WHO rolling update showed Coronavirus disease (COVID - 19) outbreak situation of 294 , 110 confirmed cases, 12, 944 confirmed deaths, and 187 countries, areas or territories with cases.

The most common symptoms at onset of COVID-19 illness are fever, cough, and fatigue, while other symptoms include sputum production, headache, haemoptysis, diarrhea, dyspnea, and lymphopenia [1]. Clinical features of COVID-19 include dry cough, fever, diarrhea, vomiting, and myalgia [6].

It is spread by human-to-human transmission via droplets or direct contact, and infection has been estimated to have mean incubation period of 6.4 days and a basic reproduction number of 2.24 - 3.58 [4]. Person-to-person transmission occurs primarily via direct contact or through droplets spread by coughing or sneezing from an infected individual [1]

\subsection{Health Risk in Tanzania}

According to [7] Tanzania is sparsely populated with population density of 51 persons per square kilometer with variation across regions. Persons are concentrated in Dar es Salaam and Mjini Magharibi regions with population densities of 3,133 and 2,581 persons per square kilometer respectively. This population density increases health risk.

To fight Covid-19, Tanzania has banned all academic and unnecessary social gatherings. Academic gatherings closed include kindergarten, primary and secondary schools, middle level colleges and Universities. Socially, Tanzania has banned unnecessary gatherings such as sports, fiesta, music performances, theatres, until further notice.

Due to low or unavailability of automatic water taps, these gatherings depend on low cost mechanical water taps. One of the problems of using mechanical water taps for hand washing is in its method of operation. Mechanical water taps need user to open handle and wash hands, then close the handle again, causing contamination.

\subsection{Problem statement}

It is perhaps clear that quarantine alone may not be sufficient to prevent the spread of COVID-19, and the global impact of this viral infection is one of heightening concern [6]. According to [6], Basic hand hygiene measures are recommended, including frequent hand washing and the use of PPE such as face masks.

Water is an indispensable input for industrial production and human existence. Currently, people are increasingly concerned about their health, and their interest in the safety of water [8]. According to [9] Clean water is a critical resource, important for the health and well-being of all humans. 
The challenge is, people use mechanical water taps. Just after washing their hands they touch the same taps, causing contamination.

The recent advances in technology have enabled the use of electronic gadgets in everyday life [10]. Everything is getting automatic and smarter with the passing of days. According to [11] automatic water faucets (taps) have become a staple in public places. They are convenient, energy efficient, hygienic and, according to manufacturers, water efficient.

Therefore, this paper comes up with designing a low cost automatic water tap which does not require a user to touch the water tap. The low cost, and green solution based automatic water tap will be used in gatherings to avoid coronavirus spreading. Such gathering places include hospitals, markets, bus stops, churches, mosques, schools, colleges, Universities, and restaurants.

\subsection{Added value of this study}

- Instead of developing a complete basin for standard hand-wash, this paper aims to design an automatic hand wash tap, which can be used simply by replacing the standard tap with the developed one. It is designed for simpler solution of performing handwash standard procedure instead of buying the whole housing of hand wash machine, hence a low cost automatic water tap.

- Other automatic water taps use solenoid, Arduino, IR sensors in creation of such circuits. These projects were machine centered designed, in such that the projects objectives were mainly on producing automation functionality and enthusiasm with technology. Arduino is suitable for prototyping, but not for led to go design for industrial production.

- The designed system is Plug and play.

- No knowledge of electronics is necessary to set-up and use the sensor. Low cost

- Uses solar power instead of electricity.

- $\quad$ Portable, small size.

- Covered to protect against direct sunlight.

- Not affected by blockage. Other systems do not need any blockage like cockroaches.

\subsection{Paper organization}

The remainder of the paper is organized as follows. Section 2 identifies related works. Section 3 presents designing the automatic water tap. Next, Section 4 offers some concluding remarks, finally section 5 gives acknowledgement.

\section{RELATED WORKS}

A study by [12] designed a system about Tap control system using the smart phones and the Arduino boards. This can be used to control the taps for plant watering and other taps in the home through internet by sitting anywhere in the world. Arduino 2560 board with Ethernet Shield is used in this project. Arduino is coded using Arduino codes and the app development is done using Android programming.

In their study [13] designed and built an automatic sensorbased water tap. The product can automatically close the tap when the user's hand is occupied and can't hold any water. However, the product is not widely adopted, since the product needs electrical power, so it needs high initial investment to build the electrical infrastructure, which most of pesantren or mosque didn't possess.

Another study was conducted in Indonesia by [14]. They developed a prototype of solar-powered, automatic water ablution tap. The system uses ultrasonic sensors to detect human presence and employs an Arduino microcontroller. It sends the "on" and "off" instructions to the relay to activate the solenoid valve to allow water flow.

According to the study by [15] they designed and implemented an automatic faucet that is user-friendly and easy to plug in regular water pipe for standard hand-washing routine. The faucet utilized IR proximity sensor to detect presence of hands that would automatically commence the hand-washing process. First, it exited water and soap simultaneously to force users to use soap. The scrubbing duration was marked by buzzer's sound and LED's light.

The mentioned systems were designed in a form of integrated automatic basin. The machines were required to be assembled as a complete basin system. Instead of developing a complete basin for standard hand-wash, this paper aims to design an automatic hand wash tap, which can be used simply by replacing the standard tap with the developed one. It is designed for simpler solution of performing hand-wash standard procedure instead of buying the whole housing of hand wash machine, hence a low cost automatic water tap.

\section{DESIGNING THE AUTOMATIC WATER TAP}

\subsection{Selection of sensor}

Three candidates were investigated. These were Infrared transceiver module, Slotted optocoupler/ photoelectric switch, and Ultrasonic Distance Sensor - HC-SR04 IR sensor.

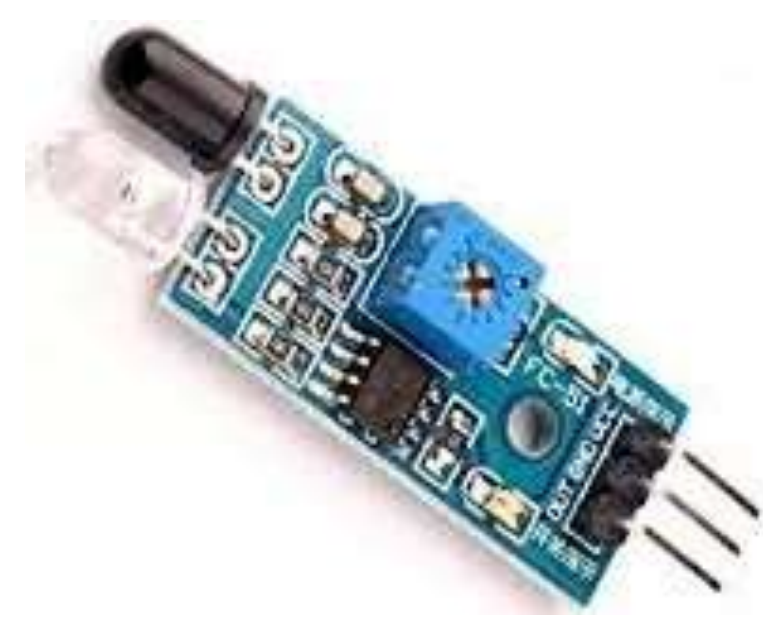

Figure 1 Infrared transceiver module. 


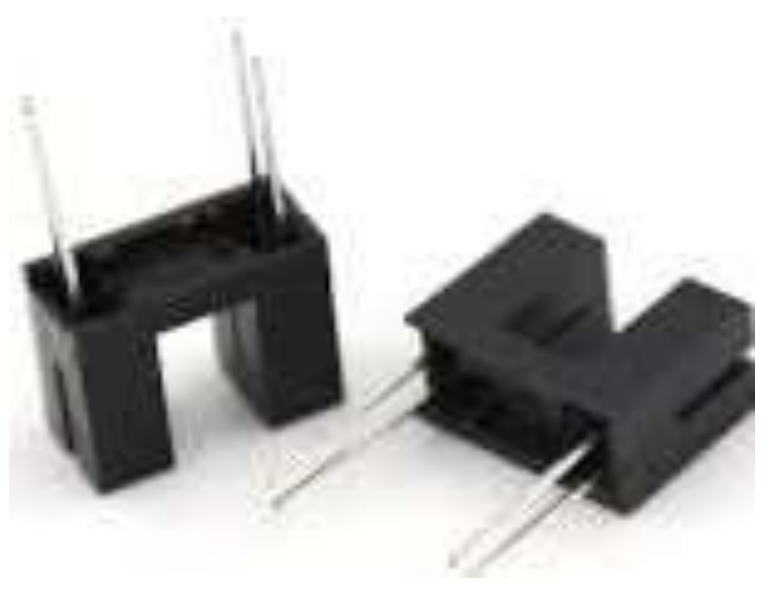

Figure 2 Slotted optocoupler/ photoelectric switch.

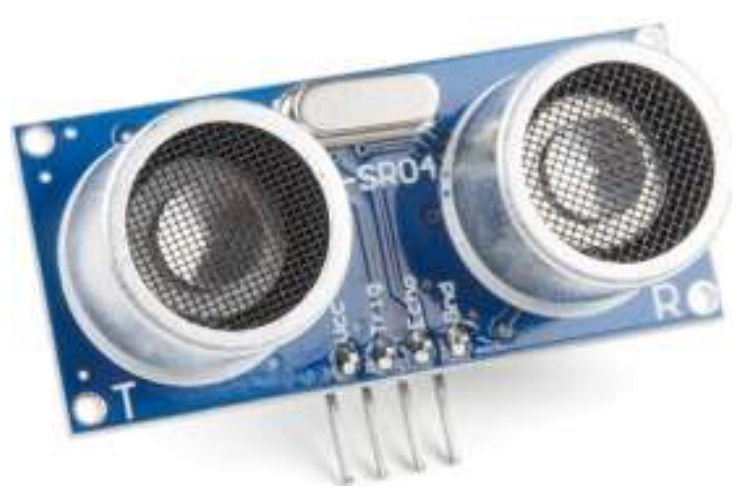

Figure 3 Ultrasonic Distance Sensor - HC-SR04 IR sensor.

The design uses Infrared transceiver module. It is small in size and it provides similar functionality as Ultrasonic Distance Sensor - HC-SR04 IR sensor.

The Slotted optocoupler/ photoelectric switch would be a best choice. However, its means of operation demands a placement of thin item about $3 \mathrm{~mm}$ inside the module. This would increase contact of shared items, hence unsuitable for the purpose.

\subsection{Selection of microcontroller in processing unit}

The selection of a microcontroller plays very important role in any embedded system. According to the need of the system a microcontroller is chosen [16]. Here in this system in order to design a low cost automatic water tap, Attity85V microcontroller is used. The microcontroller has small size of 0.34 inches in length and 0.3 inches in width (ATtiny85V datasheet, 2020). It has $8 \mathrm{~K}$ Bytes of In-System Programmable Program Memory Flash which is enough to provide intelligence that is required to control solenoid.

In this paper we design a microcontroller based automatic water tap. The microcontroller allows implementation of intelligence in the applications.

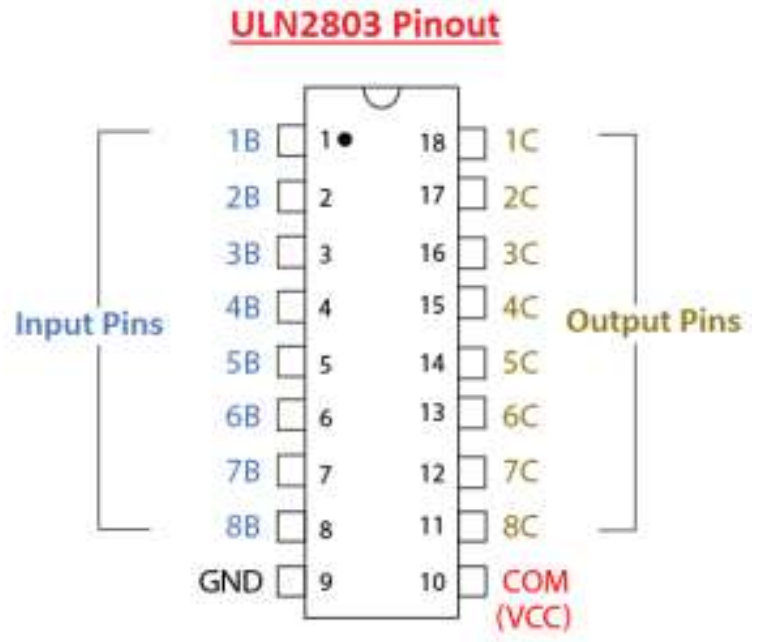

Figure 4 Attiny85V

To upload code to Attiny 85 microcontrollers during industrial mass production you will need a programmer board. The Arduino Uno is selected as a programmer for this design. It will be connected direct to pins interfaces of Attiny during upload codes. Figure 5 below shows the connections for mass production of Attiny 85 with code during production.

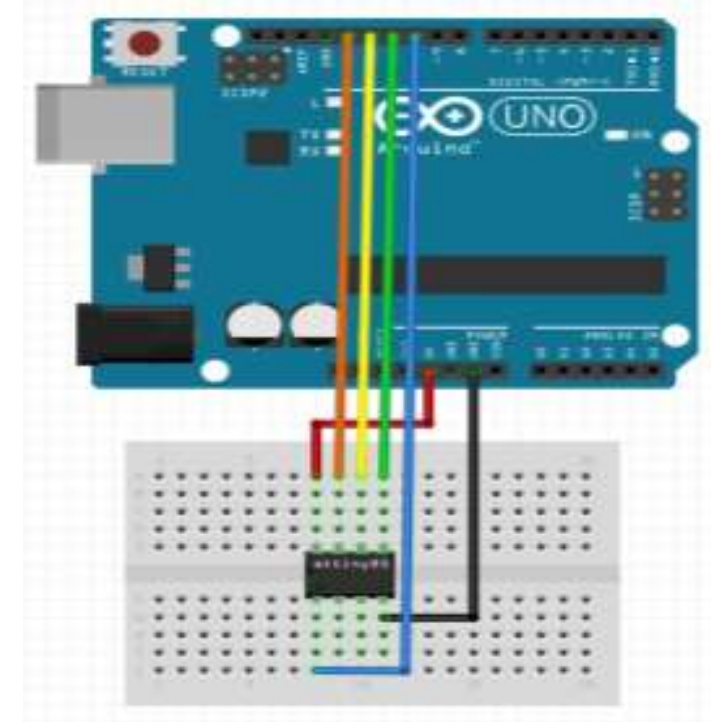

Figure 5 Attiny programming with Arduino Uno board.

The ULN2803 Darlington Transistor module will be used. This module has a capability to work with high voltage up to $50 \mathrm{~V}$. It has 8 input and 8 output connections respectively, in one to one mapping mode, meaning connection input one will produce output in output pin one. Each output pin can produce up to 500 miliAmpere. You can connect two input or more to produce additive output current of 1 Ampere or more. It has small size and fewer prices than relay and more capable than a TIP 120 transistor 


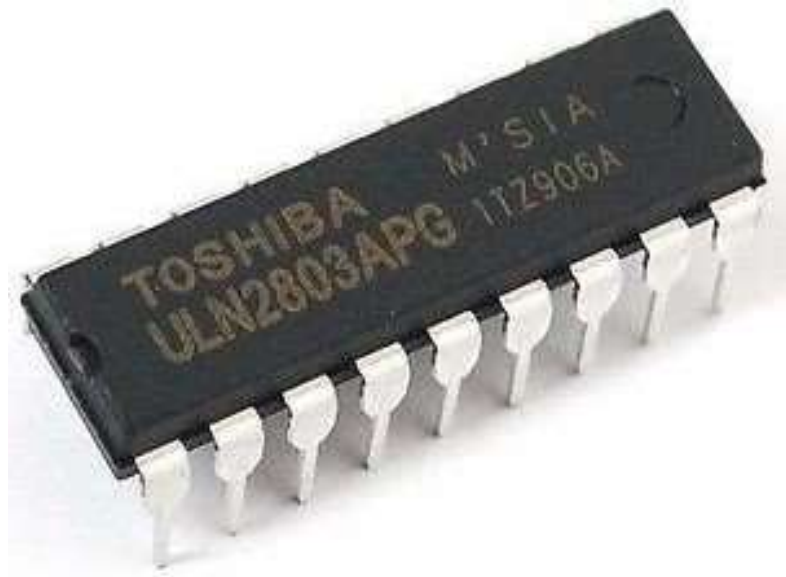

Figure 6 ULN2803 transistor.

\subsection{Selection of solenoid valve}

DC6-12V MINI Aquarium Water Pump is selected for this design. The pump can push even hot water less than 60 Celsius. Its advantages include; relatively cheaper than mini servo motors, and you do not have to worry for positive and negative pole of connections.

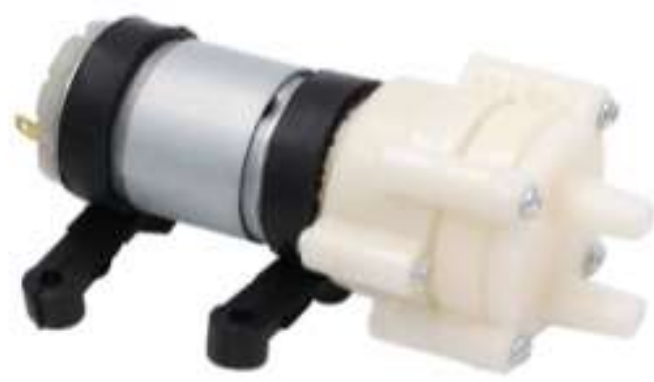

Figure 7 Mini water pump.

\subsection{Designed Automatic Water Tap}

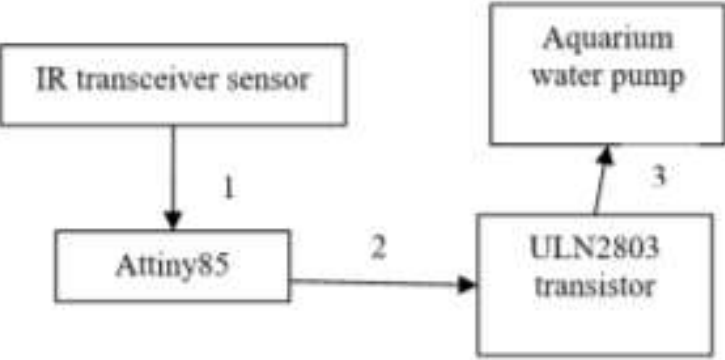

Figure 8 Block diagram of the system.
The block design shows communication flow of integrated equipment of a system. The Attiny 85 will be embedded with

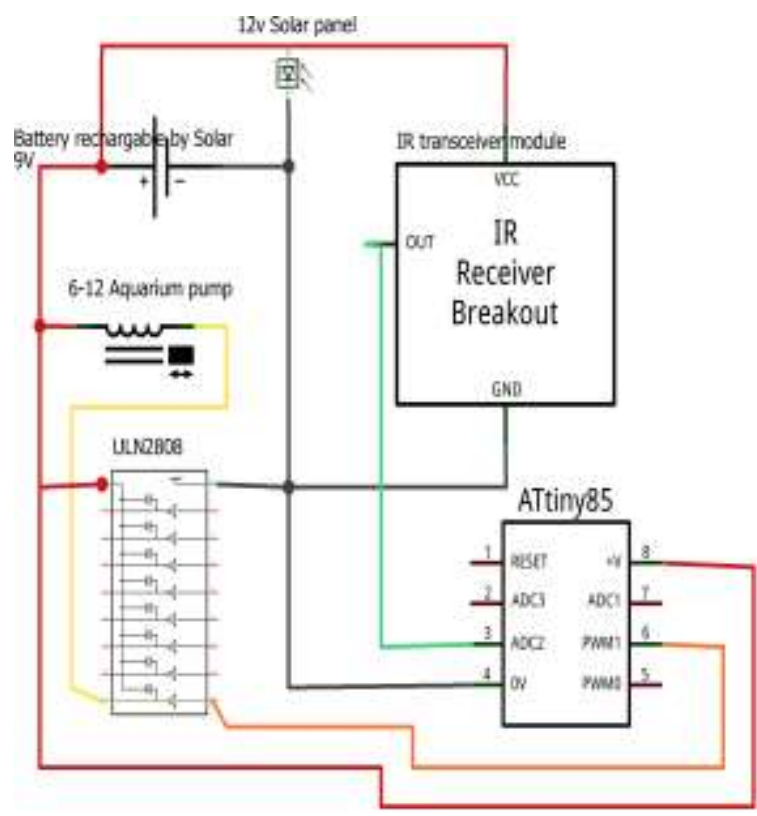

Figure 9 Circuit diagram of the system.

code by using Arduino Uno. Among conditions that code will control are duration of water flow and change of input signals, which would be resulted by hand motion in front of the sensor. The ATtiny will only send signal to ULN2803 amplifier after receiving signal from sensor and these conditions meet. The aquarium water pump is DC water pump, which works whenever supplied with minimal operating ratings. The ULN2803 will allow the rating to pump only after it receives signal from microcontroller.

From the diagram

Red line $=$ Vcc power connection

Black line $=$ Ground power connection

Yellow line= Input to pump from ULN2803/8 transistor

Orange line $=$ Input to transistor from microcontroller

Green line $=$ Input to microcontroller from sensor

The whole circuit excluding water pump will have about $6 \mathrm{~cm}$ in length and $4 \mathrm{~cm}$ in width. With PID package the components can interconnect even with double sided PCB board to reduce overall cost of production. 


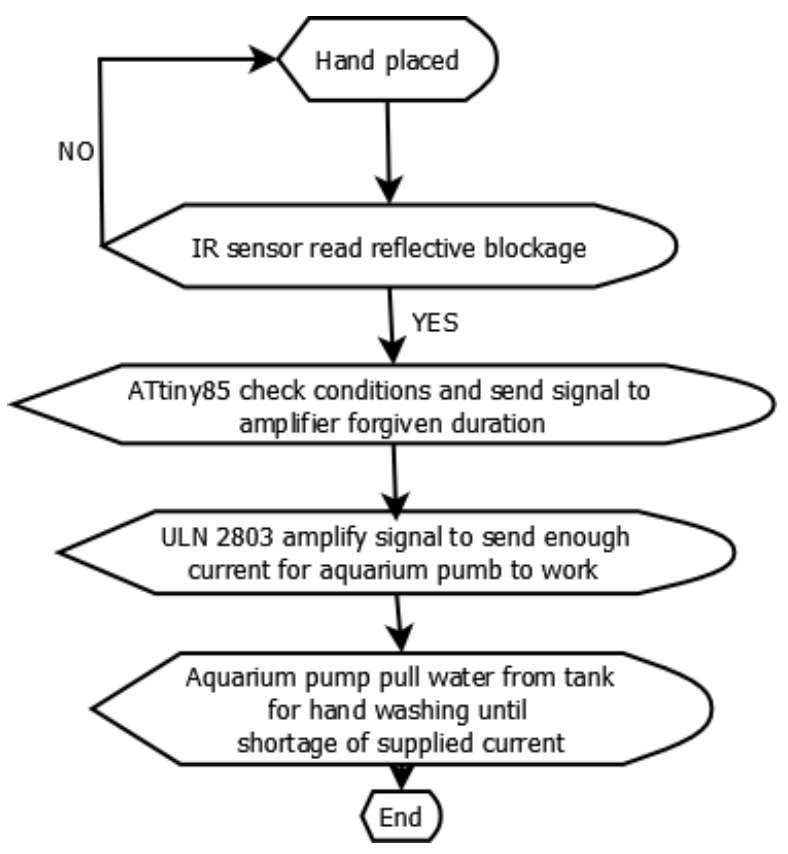

Figure 10 System operation flow diagram

\section{CONCLUSION AND FUTURE WORK}

In this paper, a low cost instrumentation system has been designed for automatic water tap which will be used to fight against Coronavirus (Covid-19). The designed system uses simple, easy to get and low cost instruments. The system does not require a user to touch the water tap. It uses microcontroller to implement intelligence, like to allow flow of water for certain duration of time to ensure proper hand washing. The solar panel will be used as a source of power. The system will use green solution based automatic water tap which will be used in gatherings to avoid Coronavirus spreading. Such gathering places include hospitals, markets, bus stops, churches, mosques, and restaurants.

Further research work is required in this direction to implement the system towards lower price for production and durability, with high sensitivity of the sensor. An implementation of the low cost automatic water tap can be extended to other liquids such as Sanitizer, milk, and juice.

\section{ACKNOWLEDGMENTS}

Authors hereby express the gratitude to the University of Iringa Staff and Students for the support.

\section{REFERENCES}

[1] H. A. Rothan and S. N. Byrareddy, "The epidemiology and pathogenesis of coronavirus disease (COVID-19) outbreak," J. Autoimmun., no. February, p. 102433, 2020, doi: 10.1016/j.jaut.2020.102433.

[2] H. Luo et al., "Can Chinese Medicine Be Used for Prevention of Corona Virus Disease 2019 (COVID-19)? A Review of Historical Classics, Research Evidence and Current Prevention Programs," Chin. J. Integr. Med., vol. 11655, no. 100029, pp. 1-8, 2020, doi: 10.1007/s11655-020-3192-6.

[3] L. Zhang and Y. Liu, "Potential interventions for novel coronavirus in China: A systematic review," J. Med.
Virol., no. January, pp. 479-490, 2020, doi: 10.1002/jmv.25707.

[4] C. C. Lai, T. P. Shih, W. C. Ko, H. J. Tang, and P. R. Hsueh, "Severe acute respiratory syndrome coronavirus 2 (SARS-CoV-2) and coronavirus disease-2019 (COVID-19): The epidemic and the challenges," Int. J. Antimicrob. Agents, vol. 2, p. 105924, 2020, doi: 10.1016/j.ijantimicag.2020.105924.

[5] M. Chinazzi et al., "The effect of travel restrictions on the spread of the 2019 novel coronavirus (COVID-19) outbreak.," Science, vol. 9757, no. March, pp. 1-12, 2020, doi: 10.1126/science.aba9757.

[6] C. Sohrabi et al., "World Health Organization declares Global Emergency: A review of the 2019 Novel Coronavirus (COVID-19)," Int. J. Surg., 2020, doi: 10.1016/j.ijsu.2020.02.034.

[7] URT, "The United republic of Tanzania. National Beaural of Statistics: 2012 Population and Housing Census Population Distribution by Administrative areas," 2013.

[8] S. Kwak, S. Yoo, and C. Kim, "Measuring the Willingness to Pay for Tap Water Quality Improvements: Results of a Contingent Valuation Survey in Pusan," Water, vol. 124, pp. 1638-1652, 2013, doi: 10.3390/w5041638.

[9] T. P. Lambrou, C. G. Panayiotou, and C. C. Anastasiou, "A low-cost system for real time monitoring and assessment of potable water quality at consumer sites," Proc. IEEE Sensors, pp. 3-6, 2012, doi: 10.1109/ICSENS.2012.6411190.

[10] H. Peter Wanga, "Designing a Machine Learning Based Framework for Enhancing Performance of Livestock Mobile Application System," Am. J. Softw. Eng. Appl., vol. 4, no. 3, p. 56, 2015, doi: 10.11648/j.ajsea.20150403.13.

[11] A. Harmon, "Do automatic water faucets actually save water?," 2016.

[12] K. Vani and P. Shrinidhi, "Automatic Tap Control System in the Smart Home using Android and Arduino," Int. J. Comput. Appl., vol. 127, no. 8, pp. 1923, 2015, doi: 10.5120/ijca2015906407.

[13] Agustiawan and A. Hadi, "Efisiensi Rancang Bangun Keran Wudhu Otomatis Hemat Air," Semin. Nas. Teknol. Informasi, Komunikasi, dan Ind. 9, pp. 18-19, 2017.

[14] S. Adriansyah Hulukati, T. Pratiwi Handayani, R. Jaya, and S. Abdussamad, "A prototype of solar-powered automatic ablution tap," IOP Conf. Ser. Mater. Sci. Eng., vol. 486, no. 1, 2019, doi: 10.1088/1757899X/486/1/012078.

[15] H. Fitriyah, E. Rosana Widasari, E. Setiawan, and B. Angga Kusuma, "Interaction design of automatic faucet for standard hand-wash," MATEC Web Conf., vol. 154, pp. 1-7, 2018, doi: 10.1051/matecconf/201815403003.

[16] R. Sood, M. Kaur, and H. Lenka, "Design and Development of Automatic Water Flowmeter," Int. J. Comput. Sci. Eng. Appl., vol. 3, no. 3, pp. 49-59, 2013, doi:

10.5121/ijcsea.2013.3306. 